\title{
MRC chronic Dyspnea Scale: Relationships with cardiopulmonary exercise testing and 6-minute walk test in idiopathic pulmonary fibrosis patients: a prospective study
}

\author{
Effrosyni D Manali¹, Panagiotis Lyberopoulos ${ }^{\dagger 1}$, Christina Triantafillidou', Likourgos F Kolilekas', \\ Christina Sotiropoulou², Joseph Milic-Emili33, Charis Roussos² and Spyros A Papiris*1
}

\begin{abstract}
Background: Exertional dyspnea is the most prominent and disabling feature in idiopathic pulmonary fibrosis (IPF). The Medical Research Chronic (MRC) chronic dyspnea score as well as physiological measurements obtained during cardiopulmonary exercise testing (CPET) and the 6-minute walk test (6MWT) are shown to provide information on the severity and survival of disease.

Methods: We prospectively recruited IPF patients and examined the relationship between the MRC score and either CPET or $6 \mathrm{MWT}$ parameters known to reflect physiologic derangements limiting exercise capacity in IPF patients

Results: Twenty-five patients with IPF were included in the study. Significant correlations were found between the MRC score and the distance $(r=-.781, p<0.001)$, the $\mathrm{SPO}_{2}$ at the initiation and the end $(r=-.542, p=0.005$ and $r=-$

$.713, p<0.001$ respectively) and the desaturation index $(r=.634, p=0.001)$ for the $6 \mathrm{MWT}$; the MRC score and $\mathrm{VO}_{2}$ peak/ $\mathrm{kg}(r=-.731, p<0.001), \mathrm{SPO}_{2}$ at peak exercise $(r=-.682, p<0.001)$, VENVCO 2 slope $(r=.731, p<0.001)$, VE $/ \mathrm{VCO}_{2}$ at AT $(r$ $=.630, p=0.002)$ and the Borg scale at peak exercise $(r=.50, p=0.01)$ for the CPET. In multiple logistic regression analysis, the only variable independently related to the MRC is the distance walked at the 6MWT.

Conclusion: In this population of IPF patients a good correlation was found between the MRC chronic dyspnoea score and physiological parameters obtained during maximal and submaximal exercise testing known to reflect ventilatory impairment and exercise limitation as well as disease severity and survival. This finding is described for the first time in the literature in this group of patients as far as we know and could explain why a simple chronic dyspnea score provides reliable prognostic information on IPF.
\end{abstract}

\section{Background}

In idiopathic pulmonary fibrosis (IPF), the combination of inflammatory and fibrotic lung parenchymal damage adversely affects lung mechanics and gas exchange and leads to progressive exertional breathlessness, the most prominent and disabling symptom in these patients [1-4]. Additionally, pulmonary vascular derangements both

* Correspondence: papiris@otenet.gr

1 2nd Pulmonary Department, "Attikon" University Hospital, Athens Medical School, National and Kapodistrian University of Athens, Greece, 1 Rimini Street, 12462, Haidari, Greece

+ Contributed equally

Full list of author information is available at the end of the article anatomic and functional $[5,6]$ as well as myocardial disturbances $[7,8]$ and peripheral muscle weakness related to the above changes $[9,10]$ are all responsible for the progressive limitation in exercise capacity characteristically observed in these patients who usually have a more rapid an swallow breathing pattern $[4,6,11-13]$.

Grading breathlessness with the aid of a variety of chronic dyspnea scales is practice in the assessment of IPF patients[14-17]. Recently, the Medical Research Council (MRC) chronic dyspnea scale has been used by several investigators including us, in the evaluation of disease severity in these patients[18,19]. The above mentioned studies have shown that the MRC score at the time

( 2010 Manali et al; licensee BioMed Central Ltd. This is an Open Access article distributed under the terms of the Creative Commons :-1/ Central Attribution License (http://creativecommons.org/licenses/by/2.0), which permits unrestricted use, distribution, and reproduction in any medium, provided the original work is properly cited. 
of diagnosis may reflect severity and outcome[18-20]. Additionally, we have shown that that the MRC score significantly correlates with the $\mathrm{CD}_{8+} \mathrm{T}$ lymphocytes in both tissue and bronchoalveolar lavage samples in these patients, subpopulation of lymphocytes that may be implicated in the pathogenesis of disease [21,22].

Previous studies have shown that physiological measurements obtained during cardiopulmonary exercise testing (CPET) [23] and the 6-minute walk test (6MWT) [24] two of the most commonly used exercise protocols may also provide information on the severity and outcome of IPF $[25,26]$ in an even more useful and reliable way than resting physiological measurements such as pulmonary function testing values and arterial blood gases, in the prognostic evaluation of IPF patients [2732]. More precisely, CPET provides an accurate assessment of abnormalities in the cardiovascular, respiratory, metabolic, peripheral muscle and neurosensory systems, under measured maximal physiological stress [23]. CPET parameters such as peak oxygen consumption $\left(\mathrm{VO}_{2}\right.$ peak), oxygen pulse, $\Delta \mathrm{Pa}_{\mathrm{O} 2} / \Delta \mathrm{V}_{\mathrm{O} 2}$, the ventilatory equivalent for carbon dioxide $\left(\mathrm{VE} / \mathrm{VCO}_{2}\right)$ at peak exercise and $\mathrm{PaO}_{2}$ slope are found to be significant predictors of survival in IPF patients $[15,33,34]$. Furthermore, parameters such as the distance walked and the level of desaturation during the 6MWT, a practical inexpensive simple walking test that examines submaximal levels of exertion, which might better reflect daily physical activities, are also found to be predictors of survival in this group of patients [27-29].

In an effort to better understand why a simple chronic dyspnea score, such as the MRC provides information on the severity and survival of IPF patients, we hypothesized that the MRC score could reflect physiologic derangements limiting exercise capacity in IPF patients. We tested our hypothesis by examining the potential relationship of the MRC score with well established and quantifiable parameters of either cardiopulmonary exercise testing or 6-minute walk test.

\section{Methods}

\section{Subjects and Setting}

This study was approved by the Institutional Ethics Committee of "Attikon" University Hospital, National and Kapodistrian University of Athens, Greece. Written informed consent was obtained from each patient. We prospectively recruited patients examined at the outpatient clinic over a period of one year. All patients fulfilled the criteria of the American Thoracic Society, European Respiratory Society and the American College of Chest Physicians for the diagnosis of IPF: Abnormal pulmonary function studies with evidence of restriction and impaired gas exchange, bibasilar reticular abnormalities with minimal ground glass opacities on high resolution computerized tomography scans, transbronchial lung biopsy or bronchoalveolar lavage showing no features to support an alternative diagnosis, age older than 50 years, insidious onset of otherwise unexplained dyspnea on exertion, duration of illness more than 3 months, bibasilar, inspiratory crackles (dry or "Velcro"-type in quality) [2,3]. Secondary causes of lung fibrosis were excluded: none of the patients had a history of environmental or occupational exposure, drug toxicity or autoimmune rheumatic disease, as documented by history, clinical and immunological tests. It is to be noted that the patients included in the present study are different new patients that have not been included in our previous studies [18,20-22].

\section{Dyspnea}

Dyspnea was assessed at diagnosis by the treating physicians (EDM, PL, CT) using the modified MRC chronic dyspnea self-administered questionnaire consisting of six questions about perceived breathlessness: 0, no dyspnea; 1 , slight dyspnea (shortness of breath when hurrying on the level or walking up a slight hill); 2, moderate dyspnea (walks slower than people of the same age on the level because of breathlessness); 3 , moderately severe dyspnea (stops because of breathlessness when walking at own pace on the level); 4, severe dyspnea (stops for breath after walking about 100 yards or after a few minutes on the level); 5, very severe dyspnea (too breathless to leave the house or breathless when dressing or undressing) $[18,19]$. The Modified Borg Scale used at both the 6MWT and CPET is described as follows: 0, no breathlessness at all, 0.5 Very, very slight, just noticeable, 1 very slight, 2 Slight breathlessness, 3 moderate, 4 some what severe, 5 severe breathlessness, 6 , 7 very severe breathlessness, 8, 9 very, very severe (almost maximum) and 10 maximum $[16,17]$.

\section{Pulmonary Functional Tests (PFTs)}

Lung function tests were done at diagnosis or at an interval not over passing 15 days at stable condition from the realization of the $6 \mathrm{MWT}$ and the CPET. PFTs included forced expiratory volume during the first second of expiration $\left(\mathrm{FEV}_{1}\right)$, forced vital capacity (FVC), total lung capacity (TLC), and single-breath carbon monoxide diffusing capacity (DLCO) all measured by MasterScreen Body apparatus (Erich Jaeger GmbH, Wuerzburg, Germany) Measurements were expressed as both percent of predicted normal and as absolute values $[35,36]$.

\section{The 6 Minute Walk Test}

The $6 \mathrm{MWT}$ test was done according to the ATS guidelines [24]. The test was performed along a measured corridor in our Department. Participants were encouraged 
to cover as much distance as possible. The following data were collected and analyzed: distance (meters), duration (minutes), saturation at the initiation of the test, saturation at the end of the test, pulse at initiation and at the end of the test, the difference in saturation before and after the test, blood pressure systolic and diastolic before the test, Borg scale score before and after the test, age (years), height (meters) and body weight (kilograms)

\section{Cardiopulmonary Exercise Testing}

The CPET was performed using a standardized protocol in accordance with the American Thoracic Society/ American College of Chest Physicians (ATS/ACCP) statement [23]. Patients were encouraged to take their medication as usual. Patients taking beta blockers were specifically excluded. On arrival at the exercise suite, patients were connected to a 12-lead electrocardiogram (Cardio Card, Oxycon Pro). Oxygen saturation was measured by digital pulse oxymetry (AutoCorr BCI) and blood pressure by a sphygmomanometer. Calibration was done according to the instructions of the manufacturers. All patients underwent a maximal or symptom-limited cardiopulmonary exercise test with an electromagnetically braked cycle ergometer (Ergometrics 900, Erich Jaeger $\mathrm{GmbH}$, Wurzburg, Germany) using a ramp protocol. All tests were monitored continuously with three leads, II, V1 and V5. The protocol included: 3 min of sitting rest, 3 min of unloaded cycling (at 60 revolutions per min. plus or minus 5 revolutions per min.), followed by a progressively increasing work rate (WR) in a ramp fashion and 3 min of recovery. The WR increment for each ramped exercise test was individualized on the basis of each patient's pretest activity level (range, 8 to $25 \mathrm{Watts} / \mathrm{min}$ ). The duration of the test was symptom-limited. Cardiopulmonary data were collected and analyzed with an exercise metabolic unit (Oxycon Pro Erich Jaeger GmbH, Wurzburg, Germany). The following parameters were recorded: Heart rate (HR), minute ventilation (VE), tidal volume (VT), peak oxygen consumption $\left(V \mathrm{O}_{2}\right.$ peak), peak oxygen consumption $/ \mathrm{Kg}\left(\mathrm{VO}_{2}\right.$ peak/Kg), \% $\mathrm{VO}_{2}$ predicted, $\mathrm{VE} / \mathrm{VCO} 2$ slope, $\mathrm{VE} / \mathrm{VCO}_{2}$ at $\mathrm{AT}, \mathrm{VT} / \mathrm{IC}$, Borg scale at peak exercise, respiratory rate (RR), total ventilation (VE), oxygen pulse $\left(\mathrm{O}_{2} \mathrm{P}\right)$, oxygen saturation $\left(\mathrm{SPO}_{2}\right)$, anaerobic threshold (AT), breathing reserve (BR), Heart rate recovery (HRR), Heart rate reserve (HRRes).

\section{Statistical analysis}

Data are presented as mean \pm standard deviation. ( \pm SD). The non-parametric Spearman correlation coefficient was calculated to describe the relationships between variables. A p-value less than 0.05 was considered significant. Furthermore for variables that were significantly correlated with MRC, simple logistic regression models were fitted to identify predictors of MRC (separated in two cat- egories, 0-2 and 3-4). Odds ratios (OR) and their 95\% confidence intervals were calculated. Variables significant at 0.05 level were also entered in multiple stepwise logistic regression analysis to examine their independent effect on MRC groups. Statistical analyses were done using SPSS v.13.0.0 (Chicago, IL).

\section{Results}

The population studied consisted of 25 patients with clinical and radiological features of IPF. The demographic and clinical characteristics of the study population at the time of IPF diagnosis are given in detail in Table 1. Seventeen patients were male with a mean age of 67.5 years $( \pm$ 8.3). Only one patient was a current smoker, the rest being no smokers (44\%) ex-smokers (52\%) respectively. Two patients had an MRC score of 0 , eight a score of 1 , eight a score of 2 , six a score of 3 and one a score of 4 . No patient included in the study had a score of 5 . The results of the PFTs are shown in Table 2. The study population had a restrictive pattern with a mean value for $\mathrm{FEV}_{1} / \mathrm{FVC}$ ratio, TLC and DLCO of $82.2 \%$ ( \pm 4.5\%), 61.4\% ( \pm $13.75 \%)$, and $45.6 \%( \pm 13.2 \%)$ respectively. Functional differences between non smokers and ex-smokers were examined and the only statistically significant difference between groups was found for FVC\% $(\mathrm{p}=0.03)$. Table 3 summarizes the results of the $6 \mathrm{MWT}$ while Table 4 the results of the CPET.

Selectively, the mean distance walked was $326.4 \mathrm{~m}( \pm$ 153.06), with a $\mathrm{SatO}_{2}$ at rest of $94.8 \%( \pm 2.2 \%)$ and a $\mathrm{SPO}_{2}$ at the end of the $6 \mathrm{MWT}$ of $87.6 \%( \pm 5.6 \%)$. The mean

Table 1: Demographic and clinical data of the study population $(n=25)$

\begin{tabular}{ll}
\hline Variables (n) & \\
\hline Age, year $(n=25)($ mean \pm SD) & $67.5( \pm 8.3)$ \\
Sex $(M / F)(n=25)$ & $17 / 8$ \\
Smoking history & \\
Ex smoker $(n) \%$ & $13(52 \%)$ \\
No smoker $(n) \%$ & $11(44 \%)$ \\
Smoker $(n) \%$ & $1(4 \%)$ \\
PY (mean \pm SD) & $25.4( \pm 34.2)$ \\
MRC chronic dyspnea score & \\
$0.0(n) \%$ & $2(8 \%)$ \\
$1.0(n) \%$ & $8(32 \%)$ \\
$2.0(n) \%$ & $8(32 \%)$ \\
$3.0(n) \%$ & $6(24 \%)$ \\
$4.0(n) \%$ & $1(4 \%)$ \\
$5.0(n) \%$ & $0(0 \%)$ \\
\hline
\end{tabular}

M/F Male/Female, PY Pack/years 
Table 2: Pulmonary Function Test Parameters of the study population $(\mathbf{n}=\mathbf{2 5})$

\begin{tabular}{llc}
\hline Parameter & $\mathbf{n}$ & Mean ( \pm SD) \\
\hline FEV $_{1}$ (Liters) & 25 & $1.95 \pm .51$ \\
$\mathrm{FEV}_{1} \%$ & 25 & $80.4 \pm 18.8$ \\
FVC (Liters) & 25 & $2.4 \pm .6$ \\
FVC\% & 25 & $77.5 \pm 21.8$ \\
TLC (Liters) & 23 & $3.5 \pm .85$ \\
TLC\% & 23 & $61.4 \pm 13.7$ \\
DLCO (mmol/min/kPa) & 23 & $3.6 \pm 1.4$ \\
DLCO $\%$ & 23 & $45.6 \pm 13.2$ \\
FEV $/$ FVC & 25 & $.82 \pm .04$
\end{tabular}

$\mathrm{FEV}_{1}$ Forced expiratory volume at 1 second, \% per cent, FVC Forced vital capacity, TLC Total Lung Capacity, DLCO Diffusion capacity for carbon monoxide, $\mathrm{FEV}_{1} / \mathrm{FVC}$ : $\mathrm{FEV}_{1} / \mathrm{FVC}$ ratio

$V \mathrm{O}_{2}$ peak was $1233.3 \mathrm{ml} / \mathrm{min}( \pm 437.6)$, the $V \mathrm{O}_{2}$ peak $/ \mathrm{kg}$ $15.5 \mathrm{ml} / \mathrm{kg} / \mathrm{min}( \pm 3.9)$ and a $\% \mathrm{VO}_{2}$ predicted $73.4 \%( \pm$ $19.1 \%)$. Four patients did not reach the anaerobic threshold, while the mean values for $\mathrm{VE} / \mathrm{VCO}_{2}$ slope, $\mathrm{VE} / \mathrm{VCO}_{2}$ at anaerobic threshold and VT/IC were $40( \pm 13.5), 41( \pm$ $10.46)$ and $0.81( \pm 0.14)$ respectively. The mean saturation of oxygen at peak exercise was $87.7 \%( \pm 5.7 \%)$ and the mean Borg scale for dyspnea at peak exercise was 4.84 ( \pm 2.3). Out of 25 patients, 16 patients (64\%) stopped CPET due to mechanical constraint and the rest $9(36 \%)$ due to leg discomfort.

To examine our hypothesis, we studied whether the MRC score at presentation was associated with any of the parameters of the 6MWT and CPET performed at maximum 15 days interval from the initial evaluation of the $\mathrm{MRC}$ at stable condition. The following correlations were found:

\section{Correlations between the MRC score and the parameters of the 6MWT}

Statistically significant correlations were found between the MRC score and the distance walked $(\mathrm{r}=-.781, \mathrm{p}<$ 0.001), the $\mathrm{SPO}_{2}$ at the initiation and at the end of the test $(\mathrm{r}=-.542, \mathrm{p}=0.005$ and $\mathrm{r}=-.713, \mathrm{p}<0.001$ respectively $)$ and the difference in saturation before and after the test $(\mathrm{r}$ $=.0634, \mathrm{p}=0.001)[$ Table 5, Figure 1] Correlations between the MRC score and parameters of the 6MWT such as the pulse at the initiation and at the end of the test, the blood pressure, and the Borg dyspnea scale were not found to be statistically significant.(data not shown)

\section{Correlations between the MRC score and the parameters of the CPET}

Statistically significant correlations were found between the MRC score and the $V \mathrm{O}_{2}$ peak $(\mathrm{r}=-.496, \mathrm{p}=0.012)$, the $\mathrm{VO}_{2}$ peak $\%(\mathrm{r}=-.481, \mathrm{p}=0.017)$, the $V \mathrm{O}_{2}$ peak $/ \mathrm{kg}(\mathrm{r}$
$=-.731, \mathrm{p}<0.001)$, the saturation of oxygen at peak exercise $(\mathrm{r}=-.682, \mathrm{p}<0.001)$, the BR peak\% $(\mathrm{r}=-.437, \mathrm{p}=$ $0.029)$, the VE/VCO2 slope $(r=.731, p<0.001)$, the HR recovery $(\mathrm{r}=-.629, \mathrm{p}=0.001)$, the $\mathrm{VE} / \mathrm{VCO}_{2}$ at $\mathrm{AT}(\mathrm{r}=$ $0.630, p=0.002)$ and the Borg scale at peak exercise $(r=$ $0.5, p=0.01$ ) [Table 6, Figure 2, Figure 3]. Correlations between the MRC score and parameters of the CPET known to reflect restrictive mechanical constraint such as the VE peak and the VT/IC were not found to be statistically significant. (Data not shown)

When applying simply logistic models for MRC categories [0-2 and 3-4] significant variables were found to be the FEV1, the FVC, the TLC, the distance walked, the $\mathrm{VO} 2$ peak, the $\mathrm{VE} / \mathrm{VCO} 2$ slope and the $\mathrm{VE} / \mathrm{VCO} 2$ at $\mathrm{AT}$. While when applying a multiple stepwise logistic regression analysis with these independent variables, the only variable independently related to the MRC score with $\mathrm{p}<$ 0.05 is the distance walked at the 6MWT. (Data not shown)

\section{Discussion}

In the present study we aimed to investigate for the first time in the literature as far as we know why a simple, clinical parameter such as the MRC chronic dyspnea score reported by the patient provides information on the severity and survival of IPF. We hypothesized that the MRC chronic dyspnea score mirrors one or multiple physiologic derangements leading to exercise limitation. Therefore the correlations between well established quantifiable features of CPET and the 6MWT with the MRC chronic dyspnea score at diagnosis were studied. According to our results, the MRC dyspnea score is significantly correlated with parameters such as the distance walked and the desaturation index of the 6MWT and with $V \mathrm{O}_{2}$ peak, the saturation of oxygen at peak exercise, the $\mathrm{BR}$ peak\%, the $\mathrm{VE} / \mathrm{VCO}_{2}$ slope, the $\mathrm{VE} / \mathrm{VCO}_{2}$ at $\mathrm{AT}$, 
Table 3: Results of the 6 minute walk test $(6 \mathrm{MWT})$ in the study population $(n=25)$ in total as well as divided in groups based on the MRC score (0-1, 2, 3-4).

\begin{tabular}{|c|c|c|c|c|c|c|c|c|c|c|c|c|}
\hline & & & & & & & & MRC & & & & \\
\hline & \multicolumn{3}{|c|}{ Total } & \multicolumn{3}{|c|}{$0-1$} & \multicolumn{3}{|c|}{2} & \multicolumn{3}{|c|}{$3-4$} \\
\hline & $\mathbf{N}$ & Mean & SD & $\mathbf{N}$ & Mean & SD & $\mathbf{N}$ & Mean & SD & $\mathbf{N}$ & Mean & SD \\
\hline Distance & 25 & 326.40 & 153.06 & 10 & 462.60 & 85.18 & 8 & 278.50 & 123.59 & 7 & 186.57 & 90.68 \\
\hline${ }^{1} \mathrm{SPO}_{2}$ at the initiation $\%$ & 25 & 94.84 & 2.23 & 10 & 96.60 & 1.51 & 8 & 93.63 & 1.51 & 7 & 93.71 & 2.29 \\
\hline${ }^{1} \mathrm{SPO}_{2}$ at the end $\%$ & 25 & 87.64 & 5.61 & 10 & 92.60 & 4.06 & 8 & 84.63 & 3.78 & 7 & 84.00 & 4.00 \\
\hline${ }^{2} \mathrm{DSPO}_{2}$ & 25 & 7.20 & 4.29 & 10 & 4.00 & 3.89 & 8 & 9.00 & 3.55 & 7 & 9.71 & 2.75 \\
\hline PULSE at the initiation & 25 & 80.16 & 13.75 & 10 & 76.00 & 13.46 & 8 & 83.00 & 17.21 & 7 & 82.86 & 9.53 \\
\hline PULSE at the end & 24 & 104.25 & 17.15 & 9 & 105.89 & 18.59 & 8 & 102.75 & 19.89 & 7 & 103.86 & 14.09 \\
\hline 3BP Systolic (mmHg) & 25 & 123.60 & 12.71 & 10 & 128.00 & 8.88 & 8 & 119.38 & 14.74 & 7 & 122.14 & 14.68 \\
\hline 3BP Diastolic (mmHg) & 25 & 76.00 & 6.45 & 10 & 78.50 & 4.12 & 8 & 75.00 & 9.26 & 7 & 73.57 & 4.76 \\
\hline BORG scale at the initiation & 25 & 0.18 & 0.35 & 10 & 0.10 & 0.32 & 8 & 0.19 & .37 & 7 & 0.29 & 0.39 \\
\hline BORG scale at the end & 25 & 2.02 & 1.75 & 10 & 1.20 & 0.89 & 8 & 2.38 & 1.77 & 7 & 2.79 & 2.34 \\
\hline
\end{tabular}

the Borg scale at peak exercise and the HR recovery of the CPET. Among all parameters of the 6MWT and the CPET examined, the MRC score is shown to better and independently reflect the distance walked at the 6MWT. Furthermore, one third of the study population stopped exercise during CPET due to leg discomfort and not to mechanical constraint.

Dyspnea is a common and disabling symptom in IPF patients. Many studies have been performed to understand the pathophysiologic mechanisms underlying dyspnea in this group of patients in an effort to better and effectively face this problem which significantly limits functional capacity and quality of life. The MRC dyspnea score has been used to grade breathlessness in patients with IPF [18-22]. The present study shows that the MRC score is strongly related to the parameters of the $6 \mathrm{MWT}$ known to better predict severity and survival in IPF patients, such as the desaturation to $\leq 88 \%$ and the dis- tance walked. We found that the higher the MRC score the shorter the distance walked and the lower the saturation of oxygen at the end of the test. Very few data exist on the literature concerning the relationship of the MRC score and the $6 \mathrm{MWT}$ in IPF. In the study of Mura et al. no correlation is found between the two, probably due to the fact that almost one third of the study population presented with both IPF and emphysema, in contrast to our patients which had no emphysema [37]. From a physiologic point of view our findings could be explained by the fact that desaturation during exercise in IPF patients reflects the overall impact of ventilation/perfusion mismatching, $\mathrm{O}_{2}$ diffusion limitation, low mixed venous $\mathrm{PO}_{2}$ and right to left intracardiac shunting in patients with a more rapid and swallow breathing pattern[6]. Walking in comparison to cycling recruits a wider range of muscle groups and results in the perception of dyspnea in disease states where oxygen delivery to peripheral muscles is lim- 
Table 4: Results of the cardiopulmonary exercise testing (CPET) in the study population $(n=25)$ in total as well as divided in groups based on the MRC score (0-1, 2, 3-4).

\begin{tabular}{|c|c|c|c|c|c|c|c|c|c|c|c|c|}
\hline & & & & \multicolumn{9}{|c|}{ MRC } \\
\hline & \multicolumn{3}{|c|}{ Total } & \multicolumn{3}{|c|}{$0-1$} & \multicolumn{3}{|c|}{2} & \multicolumn{3}{|c|}{$3-4$} \\
\hline & $\mathbf{N}$ & Mean & SD & $\mathbf{N}$ & Mean & SD & $\mathbf{N}$ & Mean & SD & $\mathbf{N}$ & Mean & SD \\
\hline $\mathrm{VO}_{2}$ peak $(\mathrm{ml} / \mathrm{min})$ & 25 & 1233.28 & 437.61 & 10 & 1391.80 & 305.87 & 8 & 1307.75 & 573.62 & 7 & 921.71 & 281.54 \\
\hline $\mathrm{VO}_{2}$ peak (\%) & 24 & 73.38 & 19.11 & 9 & 83.89 & 15.02 & 8 & 70.00 & 20.71 & 7 & 63.71 & 17.56 \\
\hline $\mathrm{VO}_{2}$ peak $/ \mathrm{kg}(\mathrm{ml} / \mathrm{kg} / \mathrm{min})$ & 25 & 15.46 & 3.90 & 10 & 18.38 & 2.68 & 8 & 14.49 & 3.24 & 7 & 12.41 & 3.40 \\
\hline AT (ml/kg/min) & 21 & 11.57 & 3.48 & 10 & 12.97 & 2.68 & 5 & 11.36 & 2.95 & 6 & 9.42 & 4.36 \\
\hline Oxygen pulse (ml/beat) & 25 & 9.19 & 2.83 & 10 & 10.16 & 2.31 & 8 & 9.51 & 3.36 & 7 & 7.44 & 2.35 \\
\hline Oxygen pulse (\%) & 24 & 78.17 & 22.62 & 9 & 92.22 & 23.69 & 8 & 70.25 & 14.27 & 7 & 69.14 & 22.36 \\
\hline $\mathrm{SPO}_{2}$ peak & 25 & 87.72 & 5.68 & 10 & 93.00 & 3.62 & 8 & 84.00 & 3.30 & 7 & 84.43 & 4.39 \\
\hline VE peak (L/min) & 25 & 54.20 & 17.52 & 10 & 56.20 & 15.82 & 8 & 54.50 & 19.26 & 7 & 51.00 & 20.03 \\
\hline VE peak (\%) & 24 & 78.08 & 19.72 & 9 & 75.89 & 17.07 & 8 & 72.50 & 15.43 & 7 & 87.29 & 26.01 \\
\hline BR peak $\%$ & 25 & 27.32 & 21.18 & 10 & 36.00 & 17.96 & 8 & 25.75 & 22.18 & 7 & 16.71 & 21.82 \\
\hline $\mathrm{VE} / \mathrm{VCO}_{2}$ & 25 & 40.00 & 13.52 & 10 & 29.00 & 6.32 & 8 & 43.13 & 12.03 & 7 & 52.14 & 10.75 \\
\hline HR reserve & 25 & 19.20 & 17.99 & 10 & 20.20 & 22.11 & 8 & 19.00 & 17.17 & 7 & 18.00 & 14.62 \\
\hline HR recovery & 25 & 14.48 & 8.30 & 10 & 19.39 & 5.76 & 8 & 13.25 & 10.48 & 7 & 8.86 & 4.34 \\
\hline $\mathrm{VE} / \mathrm{VCO}_{2}$ at $\mathrm{AT}$ & 21 & 41.00 & 10.46 & 10 & 35.10 & 3.84 & 5 & 39.20 & 7.66 & 6 & 52.33 & 11.71 \\
\hline $\mathrm{VT} / \mathrm{IC}$ & 25 & 0.81 & 0.14 & 10 & 0.82 & 0.15 & 8 & 0.82 & 0.07 & 7 & 0.80 & 0.21 \\
\hline $\begin{array}{l}\text { Borg scale at peak } \\
\text { exercise }\end{array}$ & 25 & 4.84 & 2.30 & 10 & 3.00 & 1.83 & 8 & 6.75 & 1.17 & 7 & 5.29 & 1.98 \\
\hline
\end{tabular}

All values are shown as mean \pm standard deviation (SD)

$\mathrm{VO}_{2}$ peak oxygen uptake at peak exercise, $\mathrm{AT}$ anaerobic threshold, $\mathrm{SPO}_{2}$ oxygen saturation, $\mathrm{VE}$ peak minute ventilation at peak exercise, $\mathrm{VE} / \mathrm{VCO}$ slope: slope of relationship between VE and $\mathrm{VCO}_{2}, \mathrm{HR}$ Heart rate, VT tidal volume, IC Inspiratory capacity

ited. All the above mentioned derangements are mainly related to the inability of the IPF patient to increase lung volume and displace the thorax appropriately in the setting of an increased ventilatory drive, leading to a sense of breathing effort known as dyspnea and, as we speculate, recapitulated by the MRC score in the present study $[6,10,38]$.
Among all parameters examined, the MRC score is shown to better and independently reflect the distance walked at the $6 \mathrm{MWT}$. In the literature, this parameter is considered highly reproducible and reliable as a measurement compared to oxygen consumption and oxygen desaturation that are associated with significant variation in IPF patients [32]. Along with the desaturation of oxy- 
Table 5: Statistically significant relationships between the MRC chronic dyspnea score and the parameters of the 6 minute walk test (6MWT) in the study population quantified using Spearman's rank correlation coefficient

\begin{tabular}{|c|c|c|}
\hline 6MWT parameter & & MRC score \\
\hline \multirow[t]{2}{*}{ Distance } & $r$ & -.781 \\
\hline & $\mathrm{p}$ & $<.001$ \\
\hline \multirow[t]{2}{*}{$\mathrm{SPO}_{2}$ at initiation } & $r$ & -.542 \\
\hline & $\mathrm{p}$ & .005 \\
\hline \multirow[t]{2}{*}{$\mathrm{SPO}_{2}$ at the end } & $r$ & -.713 \\
\hline & $\mathrm{p}$ & $<.001$ \\
\hline \multirow[t]{2}{*}{$\mathrm{DSPO}_{2}$} & $r$ & 0.634 \\
\hline & $\mathrm{p}$ & .001 \\
\hline
\end{tabular}

$\mathrm{SPO}_{2}$ oxygen saturation, $\mathrm{DSPO}_{2}$ difference of saturation between the end and the initiation of the test, $\mathrm{BP}$ Blood pressure

gen, the distance walked is a significant predictor of survival $[27,29]$. The distance walked is known to be related to patient effort, quadriceps strength and maximum inspiratory pressure in COPD patients [39]. In IPF patients, the distance walked is better correlated to functional parameters as well as to the alveolar-arterial gradient for oxygen[37]. In our study population significant correlation was not found between the MRC score and the Borg scale at the end of 6MWT, but a significant correlation was indeed found between the MRC score and the Borg scale at peak exercise during CPET. The Borg scale, a category scale with ratio properties, has been shown to be reproducible and responsive and ideal for the purpose of dyspnea assessment during CPET [6]. Such evidence does not exist for Borg Scale in 6MWT in IPF patients. In the literature it is shown that although desaturation is significantly more severe in IPF compared

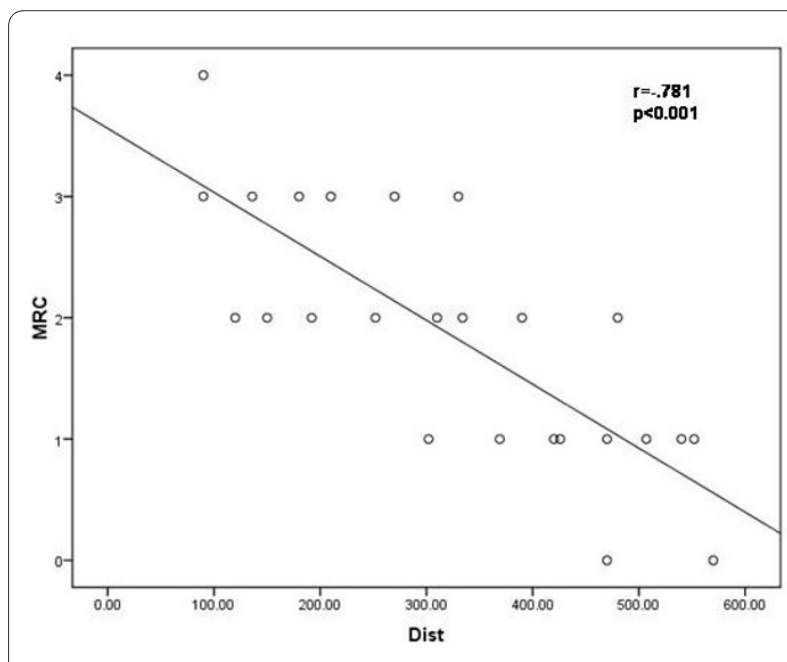

Figure 1 The correlation between the MRC chronic dyspnea score and the distance in meters walked at the 6 minute walk test in the study population $(n=25) r=-.781, p<0.001$. to COPD, dyspnoea assessed with the Borg scale is significantly more severe in COPD [17]. This could explain why this group of IPF patients with a significant desaturation during the $6 \mathrm{MWT}$ but a moderate average Borg scale walked a comparatively limited distance.

No study exists to our knowledge examining the relationship of the MRC score to CPET parameters in IPF. We found that the MRC score is significantly related to parameters reflecting ventilatory constraint such as the $V \mathrm{O}_{2}$ peak, the $V \mathrm{O}_{2}$ peak $/ \mathrm{Kg}$, the saturation of oxygen at peak exercise, the $\mathrm{VE} / \mathrm{VCO}_{2}$ slope, $\mathrm{VE} / \mathrm{VCO}_{2}$ at $\mathrm{AT}$ and the Borg scale at peak exercise. The peak oxygen consumption reflects the attainment of a limitation at some point in the oxygen conductance pathway from the lungs to the cytochrome-oxidase terminus of the electron transport chain. Thus physiologic derangements of IPF patients mentioned in the previous paragraph will be reflected in abnormally low values of this parameter, as well as of the saturation of oxygen at peak exercise $[40,41]$. Concerning the $\mathrm{VE} / \mathrm{VCO}_{2}$ slope, during CPET a close linear relation exists between carbon dioxide and minute ventilation. This relation is more linear and less variable than that between oxygen and minute ventilation and the slope can be used to describe ventilatory response to exercise. In normal subjects the slope of VE/ $\mathrm{VCO}_{2}$ reflects that 23-25 liters of VE is required to eliminate 1 liter of $\mathrm{CO}_{2}[21,40]$. In our group of patients the mean value $( \pm \mathrm{SD})$ for $\mathrm{VE} / \mathrm{VCO}_{2}$ slope was found at $40( \pm$ 13.5). An abnormal VE/ $\mathrm{VCO}_{2}$ slope (greater than 34 ) during exercise has been suggested as an independent predictor of mortality in patients with chronic heart failure and often as a correlate for advanced disease[42]. In IPF patients, this parameter has not been extensively studied but a steeper slope is related to associated reduced cardiac output during exercise, increased pulmonary artery and capillary wedge pressures, increased dead space/total 
Table 6: Statistically significant relationships between the MRC chronic dyspnea score and the parameters of the cardiopulmonary exercise testing (CPET) in the study population quantified using Spearman's rank correlation coefficient

\begin{tabular}{|c|c|c|}
\hline CPET parameter & & MRC score \\
\hline \multirow[t]{2}{*}{$\mathrm{VO}_{2}$ peak } & $r$ & -.496 \\
\hline & $\mathrm{p}$ & .012 \\
\hline \multirow{2}{*}{$\mathrm{VO}_{2}$ peak $\%$} & $r$ & -.481 \\
\hline & $\mathrm{p}$ & .017 \\
\hline \multirow[t]{2}{*}{$\mathrm{VO}_{2}$ peak $/ \mathrm{kg}$} & $r$ & -.731 \\
\hline & $\mathrm{p}$ & $<.001$ \\
\hline \multirow[t]{2}{*}{$\mathrm{SPO}_{2}$ peak } & $r$ & -.682 \\
\hline & $\mathrm{p}$ & $<.001$ \\
\hline \multirow[t]{2}{*}{ BR peak \% } & $r$ & -.437 \\
\hline & $\mathrm{p}$ & .029 \\
\hline \multirow[t]{2}{*}{ VE/ $/ \mathrm{CO}_{2}$ slope } & $r$ & .731 \\
\hline & $\mathrm{p}$ & $<0.001$ \\
\hline \multirow[t]{2}{*}{ HR recovery } & $r$ & -.629 \\
\hline & $\mathrm{p}$ & .001 \\
\hline \multirow[t]{2}{*}{$\mathrm{VE} / \mathrm{VCO}_{2}$ at $\mathrm{AT}^{*}$} & $r$ & 0.630 \\
\hline & $\mathrm{p}$ & .002 \\
\hline \multirow[t]{2}{*}{ Borg scale at peak exercise } & $r$ & 0.5 \\
\hline & $\mathrm{p}$ & .01 \\
\hline
\end{tabular}

volume ratio and increased respiratory drive leading thus to more intense perception of dyspnea.

The prevalence of leg discomfort as the limiting factor in IPF is unknown but it is likely to be significant [6]. One third of our patients stopped exercise during CPET due to leg discomfort and not to mechanical constraint.

The present study includes a homogeneous population of IPF patients with demographic and functional characteristics comparable to previous studies examining



6MWT and CPET determinants of the MRC chronic dyspnea scale as a prognostic tool in IPF $[18,20,27,28,32,43]$. However, limitations of this study consist first in the relatively small number of patients and to the lack of IPF patients with MRC score of 5 . However in patients with so high MRC scores, exercise is strongly limited leading to early completion of exercise tests before the limits of the pulmonary and cardiovascular systems are reached, which could negatively influence the results of the study

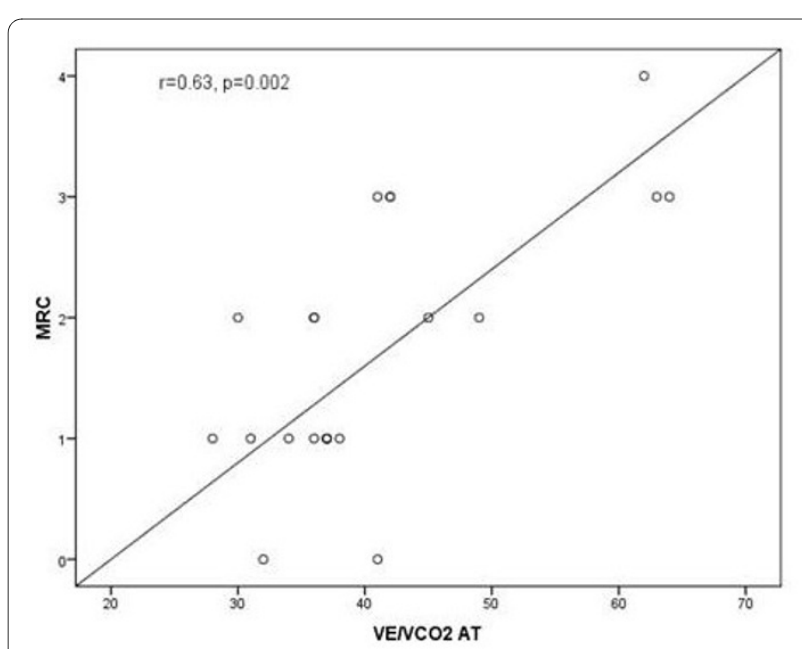

Figure 3 The correlation between the MRC chronic dyspnea score and the $\mathrm{VE} / \mathrm{VCO}_{2}$ at anaerobic threshold (AT) at cardiopulmonary exercise test in the study population $(n=25) r=.63, p<0.002$ 
[6]. Another limitation is the lack of information on the cardiac performance and pulmonary hypertension status of our patients, since data from heart ultrasounds are not included in the analysis, despite the increasing importance of the impact of pulmonary hypertension on gas exchange and exercise capacity in patients with pulmonary fibrosis[44].

\section{Conclusions}

Based on the results of our study, the fact that the MRC score predicts severity and outcome of IPF, could be explained by the finding that the MRC score is related to major functional parameters of both maximal and submaximal exercise testing known to reflect ventilatory impairment, exercise limitation and extent of disease and found to be themselves highly prognostic of survival in IPF. This finding is for the first time described in the literature as far as we know and could aid in the understanding of exercise performance and limitation in this group of patients.

\section{Abbreviations}

(AT): anaerobic threshold; (BR): breathing reserve; (CPET): cardiopulmonary exercise testing; (HR): Heart rate; (HRR): Heart rate recovery; (HRRes): Heart rate reserve; (IPF): Idiopathic pulmonary fibrosis; (MRC): Medical Research Chronic; (VE): minute ventilation; (6MWT): 6-minute walk test; $\left(\mathrm{O}_{2} \mathrm{P}\right)$ : oxygen pulse; $\left(\mathrm{SPO}_{2}\right)$ : oxygen saturation; (PFTs): Pulmonary Functional Tests; $\left(\mathrm{VO}_{2}\right.$ peak): peak oxygen consumption; $\left(\mathrm{VO}_{2}\right.$ peak/Kg): peak oxygen consumption/Kg; (RR): respiratory rate; (VT): tidal volume; (VT/IC): tidal volume/inspiratory capacity; (VE): total ventilation

\section{Competing interests}

All authors declare that no financial or other potential competing interests exist with the study matter

The study has been partly financed by the "Kapodistrias" Research Program of the National and Kapodistrian University of Athens, Greece for the Academic Year 2008-2009

\section{Authors' contributions}

EDM has contributed to the gathering and critical analysis of data and has written the manuscript. PL has conducted the cardiopulmonary exercise tests and has contributed to the interpretation of data. CT has conducted the 6MWTs, and contributed to the gathering and interpretation of all data. LFK has contributed to the critical analysis of all data and the drafting and critical review of the manuscript. CS has made the statistical analysis of data. JME and CR have contributed to the design of the study and the critical review of the manuscript. SAP has conceived of the study, has coordinated all authors and critically reviewed the data and the final version of the manuscript. All authors read and approved the final version of the manuscript.

\section{Acknowledgements}

The authors would like to thank loannis Kalomenidis, MD, PhD for his suggestions and review of the manuscript.

\section{Author Details}

12nd Pulmonary Department, "Attikon" University Hospital, Athens Medical School, National and Kapodistrian University of Athens, Greece, 1 Rimini Street, 12462, Haidari, Greece, 2Applied Biomedical Research \& Training Center "Marianthi Simou", Department of Critical Care \& Pulmonary Services, School of Medicine, National and Kapodistrian University of Athens, Ploutarchou 3, Str 10675 Greece and ${ }^{3}$ Meakins-Cristie Laboratories, McGill University, 3626 St. Urbain Str, Montreal, Quebec H2X2P2, Canada

Received: 10 January 2010 Accepted: 28 May 2010 Published: 28 May 2010
References

1. Katzenstein AL, Zisman AD, Litzky AL, Nguyen BT, Kotloff RM: Usual interstitial pneumonia. Histologic study of biopsy and explant specimens. Am J Surg Pathol 2002, 26:1567-1577.

2. American Thoracic Society; European Thoracic Society: Idiopathic interstitial pneumonias. Am J Respir Crit Care Med 2002, 165:277-304.

3. American Thoracic Society, European Respiratory Society, American College of Chest Physicians: Idiopathic Pulmonary Fibrosis, diagnosis and treatment. International Consensus statement. Am J Respir Crit Care Med 2000, 161:646-64.

4. Risk C, Epler GR, Gaensler EA: Exercise alveolar-arterial oxygen pressure difference in interstitial lung disease. Chest 1984, 5:69-74.

5. Sturani C, Papiris S, Galavotti V, Gunella G: Pulmonary vascular responsiveness at rest and during exercise in idiopathic pulmonary fibrosis: effects of oxygen and nifedipine. Respiration 1986, 50:117-129.

6. O'Donnell DE, Ora J, Webb KA, Laveneziana P, Jensen D: Mechanisms of activity related dyspnea in pulmonary diseases. Respir Physio/ Neurobiol 2009, 167:116-132.

7. Hubbard RB, Smith C, Le Jeune I, Gribbin J, Fogarty AW: The association between idiopathic pulmonary fibrosis and vascular disease. A population-based study. Am J Respir Crit Care Med 2008, 178:1257-1261

8. Papadopoulos CE, Pitsiou G, Karamitsos TD, Karvounis HI, Kontakiotis T, Giannakoulas G, Efthimiadis GK, Argyropoulou P, Parharidis GE, Bouros D: Left ventricular diastolic dysfunction in idiopathic pulmonary fibrosis: a tissue Doppler echocardiographic study. Eur Respir J 2008, 31:701-706.

9. Killian KJ, Leblanc P, Martin DH, Summers E, Jones NL, Campbell EJM: Exercise capacity and ventilatory, circulatory and symptom limitation in patients with chronic airflow limitation. Am Rev Respir Dis 1992, 146:935-940.

10. Stendardi L, Grazzini M, Gigliotti F, Lotti P, Scano G: Dyspnea and leg effort during exercise. Res Med 2005, 99:933-942.

11. Marciniuk DD, Watts RE, Gallagher CG: Dead space loading and exercise limitation in patients with interstitial lung disease. Chest 1994, 105:183-189.

12. Hansen JE, Wasserman K: Pathophysiology of activity limitation in patients with interstitial lung disease. Chest 1996, 109:1566-1576.

13. Agusti AGN, Roca J, Gea j, Wagner PD, Zaubet A, Rodringuez-Roisin R: Mechanisms of gas exchange impairment in idiopathic pulmonary fibrosis. Am Rev Respir Dis 1991, 143:219-225.

14. Baddini Martinez JA, Martinez TY, Lovetro Galhardo FP, de Castro Pereira CA: Dyspnea scales as a measure of health-related quality of life in patients with idiopathic pulmonary fibrosis. Med Sci Monit 2002, 8:CR405-410.

15. King TE Jr, Tooze JA, Schwarz MI, Brown KR, Cherniack RM: Predicting survival in idiopathic pulmonary fibrosis: scoring system and survival model. Am J Respir Crit Care Med 2001, 164:1171-1181.

16. Mahler DA, Rosiello RA, Harver A, Lentine T, McGorern JF, Daubenspeck $J A$ : Comparison of clinical dyspnea ratings and psychophysical measurements of respiratory sensation in obstructive airway disease. Am Rev Respir Dis 1987, 135:1229-1233.

17. Nishiyama O, Taniguchi H, Kondoh Y, Kimura T, Kato K, Ogawa T, Watanabe F, Arizono S: Dyspnoea at 6 minute walk test in idiopathic pulmonary fibrosis: comparison with COPD. Respir Med 2007 101:833-838

18. Papiris SA, Daniil ZD, Malagari K, Kapotsis G, Sotiropoulou C, Milic-Emili J, Roussos C: The MRC scale in the estimation of disease severity in IPF. Respir Med 2005, 99:755-761.

19. Tzanakis N, Samiou M, Lambiri I, Antoniou K, Siafakas N, Bouros D: Evaluation of health-related quality of life and dyspnea scales in patients with idiopathic pulmonary fibrosis. Correlation with pulmonary function tests. Eur J Intern Med 2005, 16:105-112.

20. Manali ED, Stathopoulos G, Kollintza A, Kalomenidis I, Sotiropoulou C, Milic Emili J, Roussos C, Daniil J, Papiris SA: Medical Research Council chronic dyspnea score predicts the survival of patients with idiopathic pulmonary fibrosis. Respir Med 2008, 102:586-592.

21. Daniil Z, Kitsanta P, Kapotsis G, Matjioudaki M, Kollintza A, Karatza M, MilicEmili J, Roussos Ch, Papiris S: $\mathrm{CD}_{8+}$ T lymphocytes in lung tissue from patients with idiopathic pulmonary fibrosis. Res Res 2005, 6:81.

22. Papiris SA, Kollintza A, Karatza M, Manali ED, Sotiropoulou C, Milic-Emili J, Roussos C, Daniil Z: CD8+ lymphocytes in bronchoalveolar lavage in idiopathic pulmonary fibrosis. J Inflamm (Lond) 2007, 4:14. 
23. ATS/ACCP Statement of cardiopulmonary testing. Am J Respir Crit Care Med 2003, 167:211-277.

24. ATS Statement: Guidelines for the 6 minute walk test. Am J Respir Crit Care Med 2002, 166:111-117.

25. Wells $A \cup$, Hirani $N$ : Interstitial lung disease guideline: the British Thoracic Society in collaboration with the Thoracic Society of Australia and New Zealand and the Irish Thoracic Society. Thorax 2008, 63:v1-v58.

26. Kawut SM, O'Shea MK, Bartels MN, et al:: Exercise testing determines survival in patients with diffuse parenchymal lung disease evaluated for lung transplantation. Respir Med 2005, 99:1431-1439.

27. Lama VN, Flaherty KR, Toews GB, Colby TV, Travis WD, Long Q, Murray S, Kazerooni EA, Gross BH, Lynch JP III, Martinez F: Prognostic value of desaturation during a 6MWT in Idiopathic pulmonary fibrosis. Am J Respir Crit Care Med 2003, 168:1084-1090.

28. Lederer DJ, Arcasoy SM, Wilt JS, D'Ovidio F, Sonett JR, Kawut SM: Sixminute walk distance predicts waiting list survival in idiopathic pulmonary fibrosis. Am J Respir Crit Care Med 2006, 174:659-664.

29. Flaherty KR, Andrei AC, Murray S, Fraley C, Colby TV, Travis WD, Lama V, Kazerooni EA, Gross BH, Toews GB, Martinez FJ: Idiopathic pulmonary fibrosis: prognostic value of changes in physiology and six-minute walk test. Am J Respir Crit Care Med 2006, 174:803-809.

30. Hallstand TS, Boitano L, Johnson WC, Spada CA, Hayes JG, Raghu G: The time walked test as a measure of severity and survival in idiopathic pulmonary fibrosis. Eur Respir J 2005, 25:96-103.

31. Lettieri CJ, Nathan SD, Browning RF, Barnett SD, Ahmad S, Shorr AF: The distance-saturation product predicts mortality in idiopathic pulmonary fibrosis. Respir Med 2006, 100:1734-1741.

32. Eaton T, Young P, Milne D, Wells AU: Six minute walk, maximal exercise tests: reproducibility in fibrotic interstitial pneumonia. Am J Respir Crit Care Med 2005, 171:1150-1157.

33. Miki K, Maekura R, Hiraga T, Okuda Y, Okamoto T, Hirotani A, Ogura T: Impairments and prognostic factors for survival in patients with idiopathic pulmonary fibrosis. Respir Med 2003, 97:482-490.

34. Fell CD, Liu LX, Motika C, Kazerooni EA, Gross BH, Travis WD, Colby TV, Murray S, Toews GB, Martinez FJ, Flaherty KR: The prognostic value of cardiopulmonary exercise testing in idiopathic pulmonary fibrosis. Am $J$ Respir Crit Care Med 2009, 179:402-407.

35. Quanjer PH, Tammeling GJ, Cotes JE, Pedersen OF, Peslin R, Yernault JC: Lung volumes and forced ventilatory flows. Report working party, Standardization of lung function tests, European Community for Steel and Coal. Official Statement of the European Respiratory Society. Eur Respir J 1993, 6(suppl 16):S5-S40.

36. Cotes JE, Chinn DJ, Quanjer PH, Roca J, Yernault JC: Standardization of the measurement of transfer factor. (Diffusing capacity). Report working party, standardization of lung function tests, European Community for Steel and Coal. Official statement of the European Respiratory Society. Eur Respir J 1993, 6(Suppl 16):S41-S52.

37. Mura M, Ferretti A, Ferro O, Zompatori M, Cavalli A, Schiavina M, Fabbri M: Functional predictors of exertional dyspnea, 6 min walking distance and HRCT fibrosis score in idiopathic pulmonary fibrosis. Respiration 2006, 73:495-502.

38. Wagner PD: Ventilation-perfusion matching during exercise. Chest 1992, 101:192S-198S.

39. Gosselink R, Troosters T, Decramer M: Peripheral muscle weakness contributes to exercise limitation in COPD. Am J Respir Crit Care Med 1996, 153:976-980.

40. Weber KT, Janicki JS, McElroy A: Determination of aerobic capacity and the severity of chronic cardiac and respiratory failure. Circulation 1987, 76:VI40-VI45.

41. Wagner PD: Determinants of maximal oxygen transport and utilization. Ann Rev Physiol 1996, 58:21-50.

42. Chua TP, Ponikowski P, Harrington D, Anker SD, Webb-Peploe K, Clark AL, Poole-Wilson PA, Coasts AJ: Clinical correlates and prognostic significance of the ventilatory response to exercise in chronic heart failure. J Am Coll Cardiol 1997, 29:1585-1590

43. ERS Task Force, Palange P, Ward SA, Carlsen KH, Casaburi R, Gallagher CG, Gosselink R, O'Donnell DE, Puente-Maestu L, Schols AM, Singh S, Whipp $\mathrm{BJ}$ : Recommendations on the use of exercise testing in clinical practice. Eur Respir J 2007, 29:185-209.

44. Gläser S, Noga O, Koch B, Opitz CF, Schmidt B, Temmesfeld B, Dörr M, Ewert R, Schäper C: Impact of pulmonary hypertension on gas exchange and exercise capacity in patients with pulmonary fibrosis. Res Med 2009, 103:317-324.

\section{Pre-publication history}

The pre-publication history for this paper can be accessed here: http://www.biomedcentral.com/1471-2466/10/32/prepub

doi: 10.1186/1471-2466-10-32

Cite this article as: Manali et al., MRC chronic Dyspnea Scale: Relationships with cardiopulmonary exercise testing and 6-minute walk test in idiopathic pulmonary fibrosis patients: a prospective study BMC Pulmonary Medicine 2010, 10:32

\section{Submit your next manuscript to BioMed Central and take full advantage of:}

- Convenient online submission

- Thorough peer review

- No space constraints or color figure charges

- Immediate publication on acceptance

- Inclusion in PubMed, CAS, Scopus and Google Scholar

- Research which is freely available for redistribution

Submit your manuscript at www.biomedcentral.com/submit
C Biomed Central 